\title{
Análise musical de peças acusmáticas com suporte de descritores psicoacústicos
}

\section{Musical analysis of acousmatic music with psychoacoustic descriptors}

\author{
(iD) Micael Antunes \\ Instituto de Artes/ Núcleo Interdisciplinar de Comunicação Sonora, \\ Universidade de Campinas, Campinas, São Paulo, Brasil \\ micaelant@gmail.com \\ iD Tales Botechia \\ Instituto de Artes/ Núcleo Interdisciplinar de Comunicação Sonora, \\ Universidade de Campinas, Campinas, São Paulo, Brasil \\ tales.botechia@gmail.com \\ iD (9) Danilo Rossetti \\ Faculdade de Comunicação e Artes, Universidade Federal \\ do Mato Grosso, Cuiabá, Mato Grosso, Brasil \\ d.a.a.rossetti@gmail.com \\ iD (9) Jônatas Manzolli \\ Instituto de Artes/ Núcleo Interdisciplinar de Comunicação Sonora, \\ Universidade de Campinas, Campinas, São Paulo, Brasil \\ jotamanzo@gmail.com
}

Resumo: Este artigo apresenta um estudo musicológico exploratório com suporte computacional que foca a análise de duas composições que utilizam as características perceptivas do som como estratégia criativa. O desenvolvimento de modelos computacionais do último século proporcionou a implementação de descritores psicoacústicos e esses tornaram-se, eventualmente, suportes para criação e análise musical. Esses estudos atuais se inserem no contexto da musicologia sistemática. Dessa forma, para analisar duas peças acusmáticas compostas pelos autores, o texto atualiza a discussão a partir do referencial teórico da psicoacústica. Apresentamos inicialmente o material composicional, 
focado em especulações sobre o temperamento por igual, e ressaltamos suas consequências psicoacústicas baseados no modelo de rugosidade. Com o objetivo de focar em aspectos da textura musical, utilizamos os seguintes descritores de áudio: o de fluxo espectral como uma ferramenta para representar fenômenos microtemporais, como a rugosidade; o de coeficientes bark, para entender o desenvolvimento da textura no plano da frequência com um viés perceptivo; e o de sharpness, para representar uma medida quantitativa de percepção de densidade. Como resultado, apresentamos os gráficos dos descritores, acompanhados de análises contextualizadas e comparativas das duas peças. Analisamos e interpretamos as características sonoras descritas neste artigo como uma propriedade emergente da textura musical. Ao final, discutimos o potencial dessa perspectiva para o campo da análise musical com suporte em modelos perceptivos.

Palavras-chave: análise musical com suporte computacional, descritores de áudio, música acusmática, sharpness, coeficientes bark.

Abstract: This article presents an exploratory study in musical analysis with a focus on perceptual features of the sound. The development of computer science of the last century afforded the study of perceptual models through technological devices, which eventually became supports for music creation and analysis. Current studies focus on the application of computational tools in the context of systematic musicology. To study two acousmatic pieces composed by the authors, the text updates this discussion based on a psychoacoustics theoretical framework. We present the compositional sound material, focused on speculations about equal-tempered scales and its psychoacoustic consequences based on roughness models. To focus on aspects of musical texture, we use the following audio descriptors: the spectral flux, as a tool to represent microtemporal phenomena, such as roughness; the bark coefficients, to understand the development of texture in the frequency domain described by a perceptive model; and sharpness, to represent a quantitative measure of perception of density. As a result, we present graphical of the descriptors, with contextualized and comparative analyzes of the two pieces. We analyze and interpret the sound features 
described in this study as an emergent property of the sound texture. Finally, we discuss the potential of new perspectives for musical analysis based on perceptual models.

Keywords: computer-aided musical analysis, audio descriptors, acousmatic music, sharpness, bark scale.

Submetido em: 27 de maio de 2020

Aceito em: 8 de janeiro de 2021 


\section{Introdução}

A composição e a musicologia têm ocupado um espaço interdisciplinar que fomenta um diálogo entre conhecimento científico sobre o som, composição e análise musical. A atuação acadêmica nesses caminhos que se cruzam pode ser entendida sob a ótica do "músico pesquisador" (RAY, 2010). É com esse ponto de vista que introduzimos o nosso tema de estudo: a análise de duas obras compostas pelos autores que têm como background especulações no campo da percepção sonora: Asperezas (2018), de Micael Antunes, e Utopia (2018), de Tales Botechia. O artigo descreve uma análise musical com suporte de modelos computacionais para elucidar como determinados fenômenos psicoacústicos podem fundamentar estratégias composicionais. As obras têm como visão estética a interação entre o espectro sonoro e a percepção de rugosidades e batimentos.

A proposta interdisciplinar do nosso estudo dialoga com as pesquisas atuais em musicologia sistemática científica (PARNCUTT, 2007), que abrange uma série de disciplinas, como vemos a seguir:

\footnotetext{
Musicologia sistemática científica (ou musicologia científica) que é primeiramente empírica e orientada a dados; ela abrange psicologia empírica e sociologia, acústica, psicologia, neurociência, ciências cognitivas, computação e tecnologia. (PARNCUTT, 2007, p. 3).
}

A fundamentação metodológica deste artigo se ancora no escopo dessa musicologia, tendo como principal referência os fenômenos perceptivos, o conhecimento experimental abarcado pelo campo da psicoacústica e os modelos computacionais. Nas próximas seções, apresentamos a fundamentação teórica que dá suporte ao nosso estudo. Primeiramente discutimos as noções de textura musical e massa sonora, passando por uma breve definição do conceito de emergência, finalizando com a apresentação dos modelos psicoacústicos utilizados na análise aqui descrita. 


\section{Textura musical e massa sonora}

A noção de textura musical é descrita na literatura como uma metáfora da percepção visual e tátil (BERRY, 1987; FERRAZ, 1990; MACKAY, 1984). Segundo Berry (1987, p. 184), a textura musical "é constituída por seus componentes sonoros; é condicionada em parte pelo número desses componentes, que soam em simultaneidade ou concorrência, e tem suas qualidades determinadas por interações". Ferraz (1990, p. 71) destaca que a textura é "compatível com o sistema e procedimentos típicos ao qual esta se insere - polifônico, monódico, harmônico, serial, pontilista, estatístico", sendo ela "a sensação gestáltica produzida pela configuração e pelo dinamismo dos elementos sonoros presentes num determinado fluxo sonoro" (FERRAZ, 1990, p. 71).

Berry (1987) afirma que a densidade é um aspecto quantitativo da textura. Esta pode ser observada a partir do número de eventos que ocorrem e da sua compressão intervalar. Essa propriedade da textura é particularmente importante para o nosso estudo, pois os processos composicionais utilizados nas peças que fazem parte deste artigo se ancoram na manipulação da compressão intervalar.

No século XX há uma exploração particular da ideia de textura a partir da noção de massas sonoras. Compositores como Gÿorgy Ligeti (1923-2006), Krzysztof Penderecki (1933-2020) e lannis Xenakis (1922-2001) ampliaram essa concepção, cada qual à sua maneira, em obras instrumentais e eletroacústicas.

A ideia de massa sonora aponta para uma condição de saturação do sistema perceptivo, pois nela se perde a sensação de intervalo musical. Ou seja, a percepção mais localizada no plano da frequência dá lugar à percepção mais global de aglomerados sonoros. Essa ideia pode ser ilustrada a partir da concepção de permeabilidade de Ligeti (2010). Segundo o compositor: 
A perda de sensibilidade dos intervalos está na origem de um estado que podemos nomear de permeabilidade. Isto significa que duas estruturas de naturezas diferentes podem ter um fluxo simultâneo, se absorver ou mesmo se fundir totalmente, modificando apenas as taxas de densidades horizontais e verticais. (LIGETI, 2010, p. 123).

Iannis Xenakis também explorou sua concepção de música estocástica alinhada à noção de massas sonoras. Ressaltamos aqui sua consciência de que suas especulações estavam conectadas com as propriedades da membrana basilar e a impulsos elétricos dos neurônios no cérebro:

Por um lado, parece que os pontos de deformação da membrana basilar têm um papel fundamental no reconhecimento; mas, de outro lado, uma espécie de código Morse temporal das descargas elétricas é levada em conta estatisticamente para a detecção de um tom (tone). Uma contagem subliminar do tempo notavelmente complexa acontece. (XENAKIS, 1992, p. 91).

Esses conceitos também fornecem subsídios para o desenvolvimento de ferramentas de suporte composicional. Vieira (2016) apresenta um estudo criativo sobre a textura musical utilizando o suporte computacional. Para tanto, o autor explora as noções de células texturais, camadas texturais e blocos sonoros. As células texturais utilizadas pelo autor se comportam como aglutinadores do processo de texturização e, portanto, a composição é o resultado da superposição hierárquica de níveis diferentes de camadas sonoras (VIEIRA, 2016).

\section{Percepção e a noção de emergência}

Os descritores de áudio fornecem modelos para extrair diversos níveis de informação do espectrograma. Bullock (2008, p. 44) 
elenca esses níveis do mais baixo para o mais alto, sendo eles: físico, sensorial, perceptivo, formal e expressivo. No contexto musicológico, esses níveis podem ser articulados a partir de concepções como a de emergência, que tem ocupado um espaço importante em trabalhos de análise e criação musical, apontando para a complexidade dos fenômenos perceptivos (ANDERSON, 2005; MERIC; SOLOMOS, 2008; ROSSETTI; MANZOLLI, 2019; SCHRÖDER, 2014). Segundo Schröder (2014, p. 38, grifo do autor), "Emergência, como um conceito da teoria dos sistemas, descreve uma nova qualidade ou Gestalt que evolui das interações do sistema e que não pode ser explicada baseada no conhecimento das interações separadamente". Nesse sentido, esse autor amplia a noção de Ferraz (1990), pois coloca que a gestalt resultante da textura musical emerge das interações dos seus elementos formadores.

Assim, entendemos que o estudo da percepção textural se vincula a um fenômeno emergente, que ocorre num nível mais alto da interação entre as partes envolvidas no processo de escuta (repertório, obra, performance, espaço acústico, ouvinte etc.), não sendo possível determinar de maneira unívoca como esse processo ocorre. Na tentativa de prospectar um recorte desses fenômenos no processo de escuta textural, utilizamos os descritores de áudio como medida das potências de determinados fenômenos psicoacústicos, os quais são produzidos pelas partes que constituem a própria textura. Ainda, segundo Di Scipio em entrevista a Anderson (2005, p. 18), o "som é o epifenômeno de um processo de baixo nível: você cria um processo de baixo nível, e as interações e interferências entre os componentes que participam do processo são ouvidos como uma forma dinâmica do som, um processo de emergência sonológica".

Convergindo com esses pontos de vista teóricos, nossa análise utiliza a psicoacústica como recorte epistêmico para o estudo da percepção textural e dessa forma aponta para algumas propriedades de baixo nível presentes na escuta. Queremos compreender as características de fenômenos de segunda ordem gerados por interações entre os componentes da textura musical. Assim, a nossa hipótese analítica é que tais características podem ser 
Análise musical de peças acusmáticas com suporte de descritores psicoacústicos

Micael Antunes · Tales Botechia • Danilo Rossetti •Jônatas Manzolli

descritas com representações dos gráficos de fluxo espectral, da escala bark ou a partir do sharpness, tal como detalharemos na seção de metodologia.

\section{Referencial da psicoacústica}

Ainda no século anterior, o estudo da música textural se apoiou em ferramentas desenvolvidas no campo da psicoacústica. As implementações utilizadas têm como fundamento a modelagem do ouvido interno, por meio do modelo de bandas críticas de Zwicker (ZWICKER, E.; FLOTTORP; STEVENS, 1957).

Os modelos psicoacústicos fornecem uma mediação entre o estímulo sonoro e a resposta sensorial (FASTL; ZWICKER, 2007). A análise musical via descritores de áudio ancorados em modelos psicoacústicos (aqui denominados de descritores psicoacústicos) tem como objetivo aproximar o resultado sonoro da gravação de uma obra com a recepção do ouvinte. Por se tratar de peças acusmáticas e, portanto, não possuírem partituras, os descritores permitem a constituição de gráficos das peças que dão suporte para a análise musical.

$\mathrm{Na}$ análise que apresentaremos, os descritores têm a propriedade de revelar nuances do timbre percebido e permitir a visualização de uma possível segmentação formal das peças. A biblioteca Libxtract (BULLOCK, 2007) e a biblioteca Mazurka (CHARM, 2020), implementadas no software Sonic Visualiser, são as ferramentas computacionais utilizadas neste estudo, pois já contam com um conjunto de rotinas que implementam os modelos aqui utilizados.

\section{Elementos das obras}

Analisamos neste trabalho duas obras acusmáticas: Asperezas (2018), de Micael Antunes, e Utopia (2018), de Tales Botechia. 
Análise musical de peças acusmáticas com suporte de descritores psicoacústicos Micael Antunes · Tales Botechia • Danilo Rossetti •Jônatas Manzolli

Ambas têm características texturais e exploram a sobreposição de diferentes camadas sonoras, operando a estrutura da composição a partir de escalas do temperamento por igual.

O temperamento por igual é definido como um sistema de afinação que consiste em dividir um determinado intervalo de altura (como uma oitava justa) em um número de partes de igual proporção (ANTUNES; FARIA, 2017; BARBOUR, 2004). No contexto da música ocidental é comumente manifesto pela divisão da oitava em 12 partes. A seguir, descreveremos algumas consequências psicoacústicas do temperamento por igual e como ele se insere nas peças aqui estudadas.

\section{Temperamento por igual e modelo de rugosidade}

Como é bem presente na literatura musical, as escalas permitem uma previsão e um dimensionamento das propriedades harmônicas decorrentes das combinações de alturas (PORRES; MANZOLLI, 2005; SETHARES, 1998) que são atravessadas historicamente pela noção de consonância (TENNEY, 1988). No início do século XIX, o trabalho de Helmholtz (1954) introduziu uma concepção de dissonância baseada em atributos psicofísicos, ressaltando a relação que há entre a composição espectral de um som e a interação com a percepção. Essa concepção é conhecida na literatura como dissonância sensorial (PORRES, 2007; SETHARES, 1998). Ou seja, uma concepção que busca investigar a dissonância a partir de seus atributos psicofísicos. O modelo de Helmholtz (1954) foi revisado por Plomp e Levelt (1965) a partir de dados coIhidos em experimentos psicoacústicos, ${ }^{1}$ revelando assim a correlação entre dissonância sensorial e as propriedades da membrana basilar. Essas propriedades são simuladas pelo modelo de bandas críticas de Zwicker, que representa a faixa de frequências audíveis

\footnotetext{
1 Voluntários expostos a estímulos sonoros (díades geradas com tons puros) eram convidados a classificar os sons em valores de 1 a 7 a partir de sua sensação de dissonância. Para um maior detalhamento de experimentos relacionados à dissonância, ver Antunes (2018).
} 
a partir de uma série de filtros auditivos (ZWICKER, E.; FLOTTORP; STEVENS, 1957), tal como detalhado no tópico 3.2 deste artigo.

O estudo das propriedades psicoacústicas das bandas críticas abriu caminho para que diversos pesquisadores e compositores explorassem o conceito de dissonância sensorial em análise e composição musical, estimando a curva de dissonância de um determinado espectro em função de uma escala musical, ou mesmo planejando os níveis de dissonância sensorial a partir da manipulação do espectro (MATHEWS et al., 1988; PIERCE, 1966; PORRES, 2007, 2012; SETHARES, 1998).

Historicamente, a noção de tensão e relaxamento associada à dissonância está principalmente atrelada ao seu papel funcional na música tonal. Por isso, é atravessada por pontos de vista estéticos e culturais que não estão, na sua totalidade, previstos no estudo da psicoacústica. Em linha com esse recorte específico, alguns autores têm defendido que os modelos de dissonância sensorial sejam entendidos como modelos de rugosidade (ANTUNES, 2018; VASSILAKIS, 2001).

Segundo Vassilakis (2001), existem três categorias perceptivas relacionadas à variação de amplitude do som: a primeira é o batimento, que ocorre quando dois sons estão em uma diferença de $1 \mathrm{~Hz}$ a cerca de $20 \mathrm{~Hz}$. A segunda é a rugosidade, que se inicia no limiar da percepção de batimentos até atingir um pico em 1/4 da banda crítica. Depois decai até atingir uma diferença maior que a de uma banda crítica. Nesse estado há uma ausência de percepção de variação de amplitude (VASSILAKIS, 2001, p. 3-4). Sendo assim, as propriedades da cóclea e do ouvido interno desempenham um papel considerável na sensação de dissonância, mas não explicam completamente o fenômeno em si, que é multidimensional. Esse é também o ponto de vista que adotamos neste trabalho. 


\title{
Contextualização das peças
}

\author{
Asperezas (2018)
}

A peça Asperezas teve como ponto de partida a definição de Vassilakis (2001) sobre a rugosidade, apresentada na seção anterior, que prevê a sensação de rugosidade iniciando a partir da diferença de $20 \mathrm{~Hz}$ entre tons puros e com sua presença associada ao tamanho da banda crítica. A partir dessa definição, a composição explora uma passagem contínua entre batimentos, rugosidade e ausência de variação de amplitude.

A peça foi inteiramente composta a partir da aplicação de um modelo computacional de Síntese por Modulação de Frequência (Síntese FM), ${ }^{2}$ utilizando o Sintetizador Helm como gerador dos sons.3 A estrutura da peça ancora-se em dois procedimentos de modulação da Síntese FM: a) variação da frequência da onda moduladora no entorno da frequência da onda portadora, para assim produzir uma variação contínua de batimentos e rugosidades; b) variação do índice de modulação4 da Síntese FM, para assim produzir uma variação contínua no espectro sonoro resultante.

O primeiro aspecto foi modelado na programação, fazendo com que o sinal ou onda portadora (onda triangular) tenha frequências e amplitudes fixas, extraídas de uma escala do temperamento por igual (12 partes, ver Tab. 1) e alteradas a cada seção da peça. Já o sinal ou onda moduladora possui uma mudança contínua de sua frequência e amplitude, com valores de frequência central igual a da onda portadora. O índice de modulação é variado continuamente, modificando assim a quantidade de parciais do espectro.

Utilizando os dois procedimentos de manipulação da Síntese FM, obtém-se o resultado de uma contínua transformação espectral

\footnotetext{
2 Processo de síntese não linear onde uma onda portadora é modulada pela frequência e amplitude da onda moduladora. Por meio desse processo, é possível manipular a riqueza de um espectro sonoro, bem como suas qualidades harmônicas. Para um entendimento mais amplo do processo de síntese FM, Cf. Chowning (1973).

3 O sintetizador Helm também utiliza modulação de fase em conjunto com a modulação FM. Para uma descrição detalhada da técnica de síntese utilizada e de seus parâmetros, ver Antunes (2018, p. 72-78).

40 índice de modulação define a quantidade de modulação que a onda moduladora aplicará na onda portadora. No espectro que resulta da síntese, significa que quanto maior o índice de modulação, maior o número de parciais no espectro.
} 
Análise musical de peças acusmáticas com suporte de descritores psicoacústicos Micael Antunes · Tales Botechia • Danilo Rossetti •Jônatas Manzolli

e de intensidade. A segunda, em virtude também do mecanismo de cancelamento produzido pelos batimentos, que alternam interferências que aumentam e diminuem a intensidade do sinal. Essas duas transformações somadas visam à reprodução dos fenômenos perceptivos de flutuação de amplitude destacados por Vassilakis (2001). Cada seção da peça tem uma ou mais frequências centrais extraídas de uma escala do temperamento por igual em 12 partes (Quadro 1). A peça é planejada em 11 seções, cada qual com sua frequência central, tal como expostas em valores arredondados no Quadro 1. A peça inicia com relações harmônicas entre essas frequências centrais, que caminham no decorrer da peça para relações de inarmonicidade. 50 resultado sonoro final é uma crescente evolução de características perceptivas de densidade, relacionada com a quantidade de parciais e energia do espectro, além do seu registro e rugosidade, a partir das interações entre os parciais do espectro.

Quadro 1 - Frequências centrais da síntese FM em Asperezas

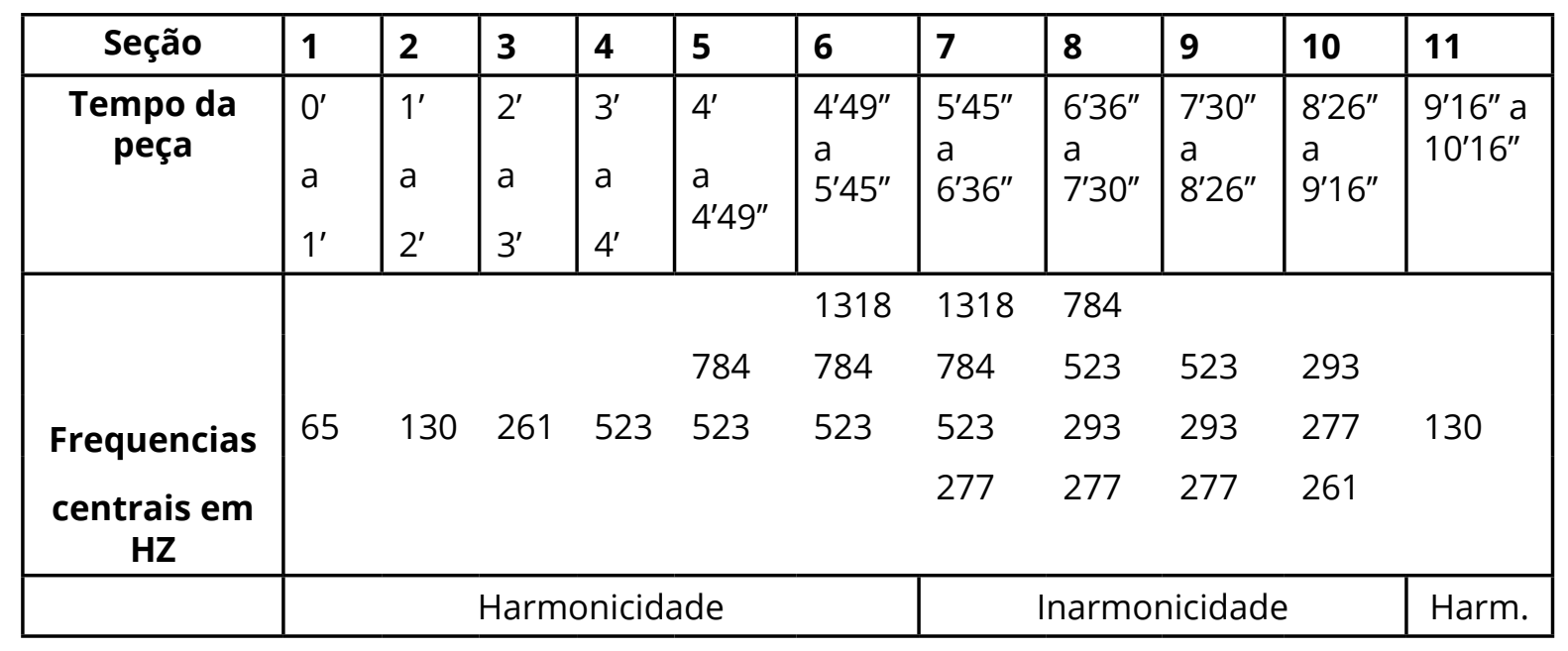

Fonte: Elaborado pelos autores.

Descrição de imagem: O quadro exibe na linha 3 as frequências centrais (arredondadas) da síntese FM de Asperezas para cada seção da composição (linha 1) e de acordo com o respectivo tempo inicial e final (linha 2). Além disso, indica na última linha os

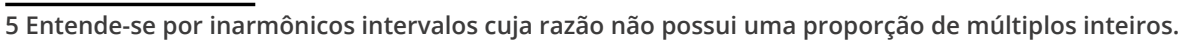


Análise musical de peças acusmáticas com suporte de descritores psicoacústicos Micael Antunes · Tales Botechia • Danilo Rossetti •Jônatas Manzolli

momentos em que as frequências centrais estão em uma relação de harmonicidade ou inarmonicidade.

A fim de ilustrar as propriedades do material composicional de Asperezas, apresentamos na Figura 1 uma curva que estima a sensação de rugosidade esperada, com 1, 4, 8, 12 e 16 componentes espectrais de uma onda dente-de-serra. ${ }^{6}$ Essa curva foi gerada a partir do modelo de Vassilakis (2001). A rugosidade é plotada em função das díades da escala 12-tet,7 que são formadas pelo grau 0 mais o grau $\mathrm{n}$ da escala.

Nessa figura conseguimos visualizar como a rugosidade estimada muda conforme a quantidade de parciais do espectro. Com um parcial existe apenas um pequeno relevo na díade 0-1, com um decaimento que chega a 0 na díade 0-5 e permanece assim até a díade 0-12. De outra maneira, com 16 parciais há um perfil de rugosidade mais complexo e com níveis muito mais altos. Observamos também que há um decaimento da rugosidade proporcional à distância das fundamentais de uma díade. Vide mais informações sobre a curva de rugosidade em Antunes (2018), Sethares (1998) e Vassilakis (2001).

Figura 1 - Rugosidade em função de uma escala 12-tet, para um espectro de uma onda dente-de-serra com $n$ parciais.

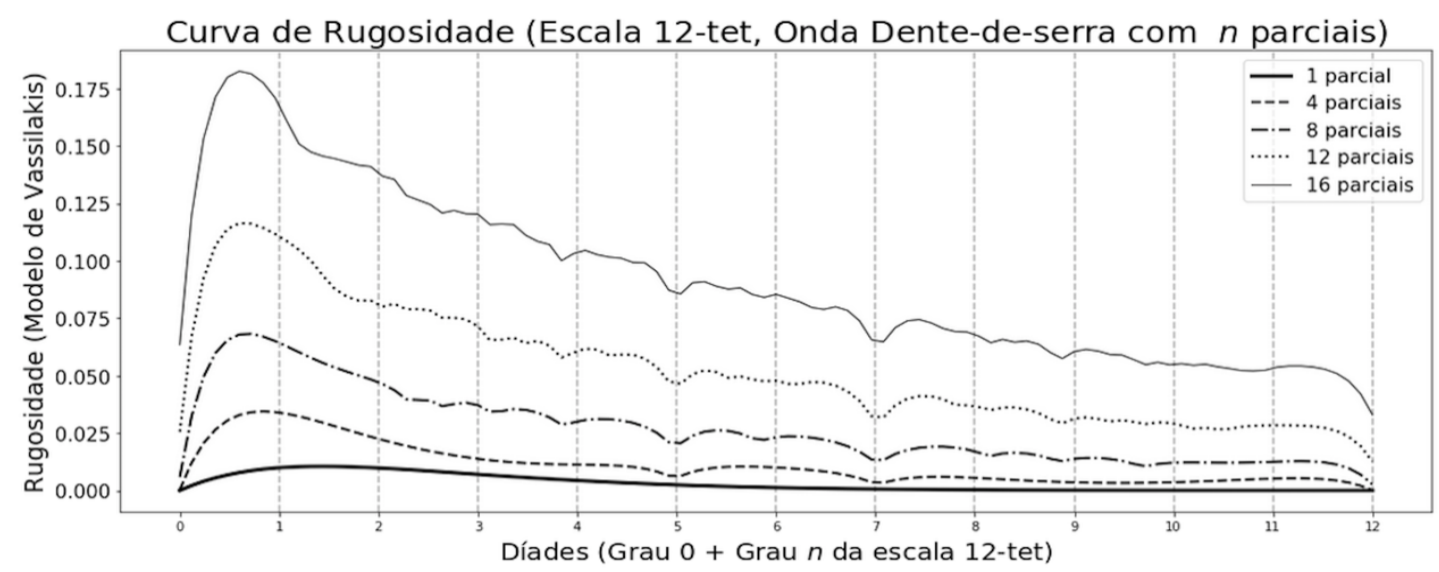

Fonte: Elaborada pelos autores.

6 Que possui parciais harmônicos com amplitudes de 1/parcial.

7 Do inglês, tempered equal tone. 
Análise musical de peças acusmáticas com suporte de descritores psicoacústicos Micael Antunes · Tales Botechia • Danilo Rossetti •Jônatas Manzolli

Descrição da imagem: Curvas de rugosidade para uma onda dente de serra com 1, 4, 8, 12 e 16 parciais plotadas em função de intervalos da escala 12-tet. O eixo vertical representa o nível de rugosidade e o horizontal os intervalos da escala 12-tet.

\section{Utopia (2018)}

Em Utopia (2018), de Tales Botechia, o material harmônico da peça foi criado a partir do temperamento por igual em 53 partes da oitava. A forma da peça foi construída como um arco, cujo elemento que se desenvolve de modo mais proeminente é uma textura constituída de 7 alturas da escala temperada em 53 partes escolhidas aleatoriamente pelo computador. Seguindo o arco, essa textura aumenta em intensidade e em seu âmbito de oitavas, expandindo-se até uma distribuição de 5 oitavas (vide Fig. 2). As transições de expansão e contração dessa textura são marcadas por uma unidade sonora em que se pode perceber a sequência de dois acordes, sendo o primeiro em fade in e o seguinte em fade out.

Figura 2 - Esquema geral da composição de Utopia.

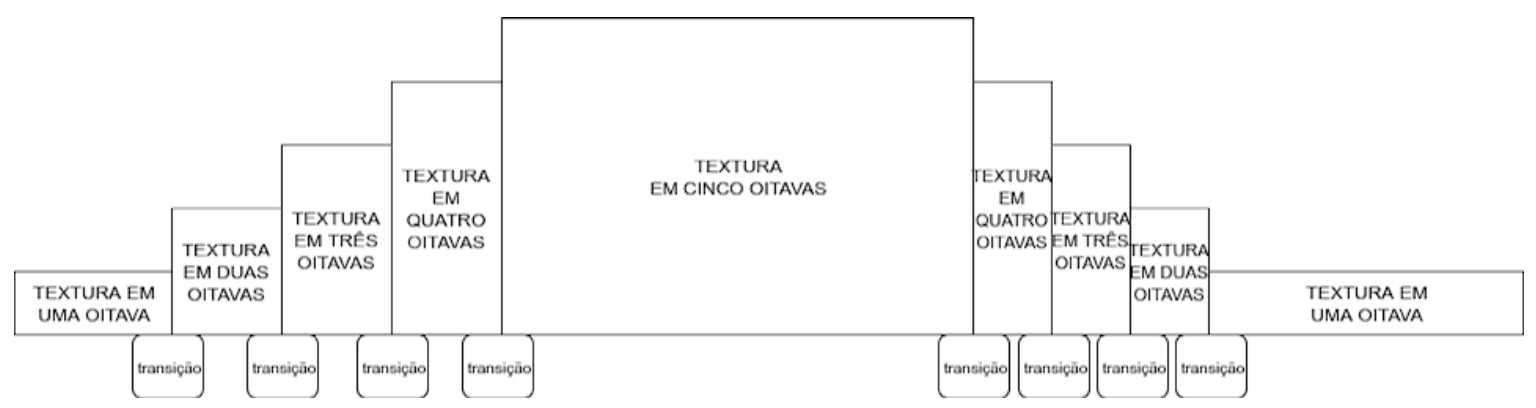

Fonte: Elaborada pelos autores.

Descrição da imagem: A série de retângulos representa a extensão da textura em número de oitavas (eixo vertical) em função de sua duração no tempo (eixo horizontal). Os quadrados abaixo da figura representam os momentos de transição da composição.

A respeito da textura principal da peça, cada uma de suas 7 alturas é elaborada utilizando um modelo de síntese subtrativa 
Análise musical de peças acusmáticas com suporte de descritores psicoacústicos Micael Antunes · Tales Botechia • Danilo Rossetti •Jônatas Manzolli

com ruído rosa ${ }^{8}$ com uma fundamental e outros 3 parciais de oitava. Esses parciais tornam-se proporcionalmente mais audíveis de acordo com a intensidade enviada ao sintetizador. Tons puros alternam rapidamente e aleatoriamente entre os primeiros 16 parciais e com desvios de 7 ou $8 \mathrm{~Hz}$ em relação às frequências da série harmônica. Essas 7 alturas, por sua vez, criam micro arcos de intensidade em fade in/out, cada uma com uma duração própria, gerando uma densidade sempre mutável no resultado final da textura (vide Fig. 2, acima).

A unidade sonora que indica a transição é feita por uma passagem entre ruído rosa filtrado e ondas dente-de-serra. Outras sínteses, com sons de ataques mais pontuais, também permeiam a peça, sempre explorando a divisão escalar de 53 partes por oitava.

Com o objetivo de criar um paralelo com o material musical de Asperezas, exibimos na Figura 3 o nível de rugosidade para uma escala que divide a oitava em 53 partes iguais. A rugosidade é plotada em função das díades da escala 53-tet, que são formadas pelo grau 0 mais o grau $n$ da escala:

Figura 3 - Rugosidade em função de uma escala 53-tet, para um espectro de uma onda dente-de-serra com 20 parciais.

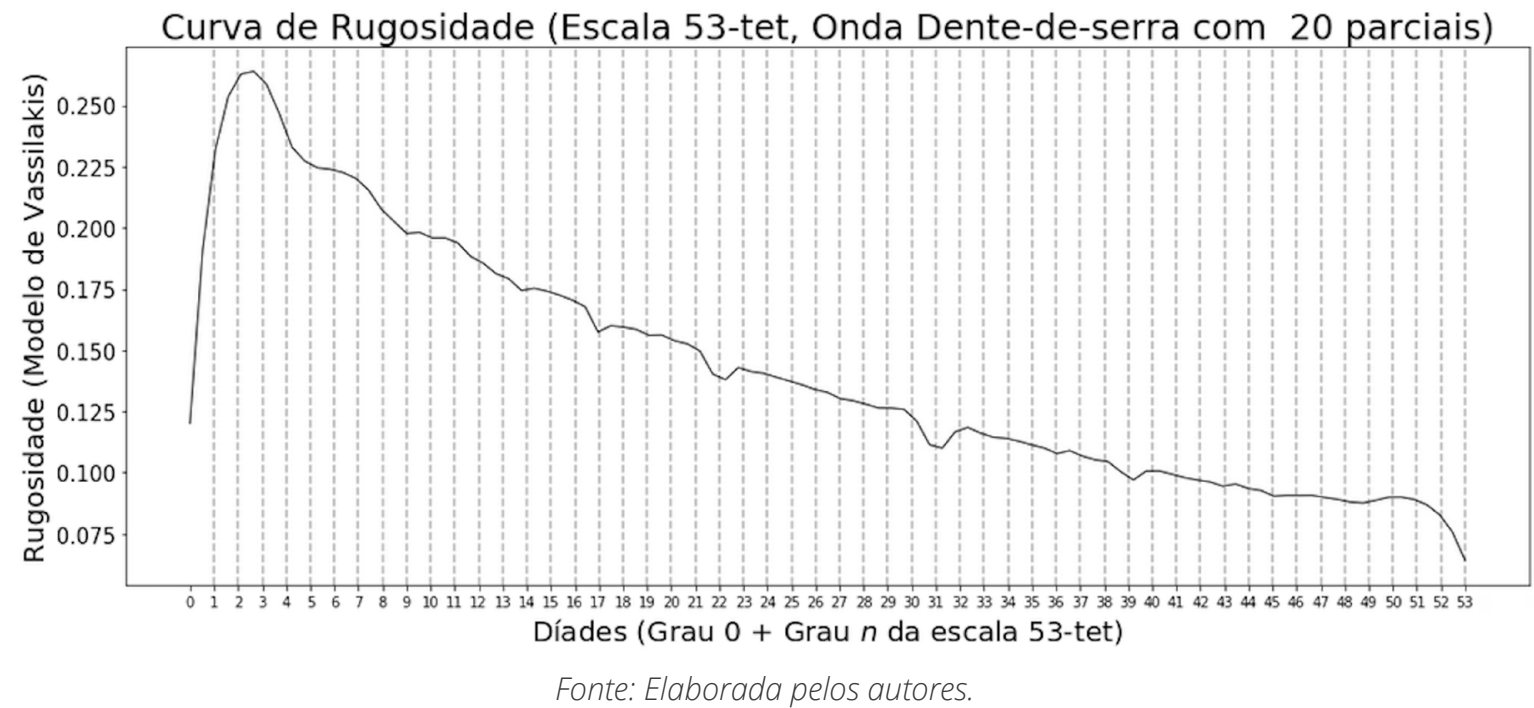

8 Puckette (2007, p. 250, grifo nosso) define a síntese subtrativa como “a técnica de usar filtros para modelar o envelope espectral de um som, formando outro som, geralmente preservando qualidades do som original tais quais altura, roughness (rugosidade), noisiness (nível de ruído), ou graniness (granularidade)". 
Descrição da imagem: Curvas de rugosidade para uma onda dente de serra com 20 parciais plotadas em função de intervalos da escala 53-tet. O eixo vertical representa o nível de rugosidade e o horizontal os intervalos da escala 12-tet.

A Figura 3 nos revela que, quando comparamos uma escala 53-tet com uma escala 12-tet, os tamanhos dos intervalos resultam em uma maior variedade de níveis de rugosidade e a maior possibilidade de sua manipulação. Por exemplo, temos grandes níveis de rugosidade nos passos de 1 a 9 da escala. Também possuímos intervalos bem alinhados com as mínimas de rugosidade do espectro, como nos graus 17, 22, 31 e 39 da escala.

\section{Metodologia da análise}

Estudos sobre a percepção apresentam a possibilidade de que a mesma possa ser observada a partir do estímulo físico e pela resposta do nosso aparato fisiológico (FASTL; ZWICKER, 2007). Dado que já destacamos o diálogo que as composições aqui estudadas possuem com a psicoacústica, a nossa metodologia analítica tem por objetivo entender como o material sonoro das duas obras aqui analisadas exploram esses fenômenos nos seus desenvolvimentos musicais específicos. Buscamos também analisar como essas propriedades de modelos psicoacústicos fomentam a emergência das respectivas formas musicais. Para tanto, utilizamos três descritores: o de fluxo espectral, pertencente à biblioteca Mazurka (CHARM, 2020); o de coeficientes barks, a partir do modelo de bandas críticas de Zwicker (ZWICKER, E.; FLOTTORP; STEVENS, 1957); e o de sharpness, sendo estes dois últimos pertencentes a biblioteca Libxtrac (BULLOCK, 2007) e cuja fundamentação teórica será detaIhada brevemente a seguir. 


\section{Fluxo espectral}

Dentre os parâmetros perceptuais mais relevantes presentes na dinâmica do envelope espectral está a variação da amplitude de suas componentes. Vassilakis (2001) dedicou um extenso trabalho buscando evidenciar como a flutuação da amplitude das parciais do espectro é explorada musicalmente em diversos contextos culturais, como nos cantos rurais bósnios denominados ganga e na execução de instrumentos do oriente médio como o mijwis ${ }^{9}$ (VASSILAKIS, 2001, p. 8). O que esse estudo evidencia é que tais fenômenos são condicionados pelas características dos estímulos físicos junto com a resposta neurofisiológica do nosso sistema auditivo (VASSILAKIS, 2001; ZWICKER, E.; FLOTTORP; STEVENS, 1957; FASTL; ZWICKER, 2007).

No contexto da música eletroacústica, a flutuação de amplitude das componentes do espectro sonoro é amplamente explorada e pode ser consequência do uso de diversas técnicas de tratamento sonoro. Entendemos que os fenômenos de flutuação de amplitude ocorrem em uma escala microtemporal que, segundo Roads (2001, p. 4), se referem a "partículas de som em uma escala de tempo que se estende até o limite de percepção auditiva (medido em milésimos de segundo ou milissegundos)".

Deveras, esses fenômenos de flutuação foram explorados pelos compositores nas duas peças em análise. Para tanto, utilizaram a interação de intervalos musicais atrelados a escalas do temperamento por igual e, por isso, utilizamos um descritor de áudio que quantifique tal flutuação. Assim, introduzimos o descritor de fluxo espectral, que é definido como a distância Euclidiana (norma 12) entre as magnitudes das componentes espectrais de 2 janelas de análises sucessivas (CHARM, 2020), que pode ser representado pela Equação 1:

$\overline{9 \text { Uma flauta de cano }}$ duplo que permite a execução de duas alturas simultaneamente. 


$$
F=\sum_{k=1}^{K}\left|M_{k n}-M_{k n-1}\right|^{2}
$$

onde $n=1,2,3 \ldots . . N$ é o índice da janela de análise e a magnitude do bin da fft. Sendo assim, é possível a partir da Equação 1 medir o nível de flutuação da amplitude do espectro, calculando a diferença das magnitudes entre duas janelas de análise consecutivas. Desse modo, quanto maior a variação nas magnitudes do espectro entre duas janelas consecutivas, maior o fluxo. Na nossa análise, a variação das magnitudes espectrais está relacionada à percepção das flutuações de amplitude que utilizamos no processo composicional. O nosso objetivo é descrever eventos microtemporais.

\section{Modelo de bandas críticas de Zwicker}

Diversos modelos têm por objetivo a simulação do comportamento do ouvido interno utilizando um conjunto de filtros auditivos. É o caso do modelo MFCC (PEETERS, 2004) e do descritor que utilizamos no nosso estudo, chamados de coeficientes bark (BULLOCK, 2008, p. 76). A medida de um bark equivale a unidade mínima do modelo de bandas críticas que representa o espectro de frequências audíveis baseada nas divisões da membrana basilar e em dados experimentais formalizados por ZWICKER; FLOTTORP; STEVENS (1957). Segundo o prognóstico de modelos psicoacúticos, quanto mais frequências estimulam um determinado ponto da membrana basilar, menor é a nossa capacidade de distinguir tais frequências. Isso tem como consequência fenômenos de mascaramento, nos quais frequência(s) deixam de ser ouvidas por conta da composição espectral, e do já citado fenômeno da rugosidade. O descritor de coeficientes bark possibilita a observação da quantidade de energia em cada uma das bandas críticas.

Utilizando as ideias apresentadas na sessão sobre textura e massa sonora, entendemos que os coeficientes bark podem representar o comportamento textural a partir da quantidade de energia nas bandas críticas. Assim, fornece uma maneira de descrever 
a saturação gerada no aparato perceptivo e a noção de permeabilidade, já discutidas acima.

O modelo de bandas críticas de Zwicker prevê uma modelização dos filtros auditivos abrangendo frequências até $15.5 \mathrm{kHz}$. Tomando como referência o teorema de Nyquist, isso significa que o modelo permite a análise de áudio com a taxa de amostragem máxima de 31 kHz (SMITH; ABEL, 1999). A partir dessa constatação, apresentamos uma função que permite uma conversão aproximada da escala bark em $\mathrm{Hz}$ com o objetivo de extrapolar o modelo até $27 \mathrm{kHz}$, permitindo a representação do áudio até uma taxa de amostragem de 54 kHz (BULLOCK, 2008, p. 76). Essa aproximação é dada pela Equação 2:

$$
B=13 \tan ^{-1}\left(7.6 * 10^{-4} f\right)+3.5 \tan ^{-1}\left(\frac{f}{7500}\right)^{2}(2)
$$

Essa equação foi utilizada por Bullock (2008, p. 76) em sua implementação na Libxtract para definir as frequências limites de cada banda bark. Utiliza assim as frequências: 0, 100, 200, 300, 400, 510, 630, 770, 920, 1080, 1270, 1480, 1720, 2000, 2320, 2700, 3150, 3700, 4400, 5300, 6400, 7700, 9500, 12000, 15500, 20500, 27000 para os barks de 0 a 25, totalizando assim 26 barks (BULLOCK, 2020).

Na nossa análise, essa escala é utilizada para indicar a distribuição de energia por bandas da escala bark, geradas pelos processos composicionais desenvolvidos pelos autores. O objetivo é estimar a distribuição em bandas de frequência dos componentes texturais das duas obras.

\section{Modelo de sharpness}

Segundo Fastl e Zwicker (2007), diversos parâmetros piscoacústicos são úteis para a investigação da percepção de fenômenos sonoros. Esses parâmetros são relevantes, pois temos como muito bem definidas e delimitadas as sensações de altura e intensidade 
de um som, e o que escapa a esses dois parâmetros, frequentemente atribuímos a um lugar comum que chamamos de timbre (FASTL; ZWICKER, 2007, p. 239). Caberia, portanto, à psicoacústica investigar diferentes dimensões presentes na percepção do que chamamos genericamente de timbre.

Um desses parâmetros é conhecido como sharpness e, segundo os autores, está relacionado à sensação de densidade de um som (FASTL; ZWICKER, 2007, p. 239). A noção de sharpness pode ser estudada de maneira separada e demonstra uma consistência quando submetida a estudos experimentais com um grande número de voluntários.

O já apresentado modelo de bandas críticas é também utilizado no descritor de sharpness. O modelo preconiza que, quanto maior a banda de ruído e quanto maior a taxa bark (B), maior o sharpness.

A Equação 3, extraída de Bullock (2007, p. 69), representa o modelo de sharpness. A unidade do modelo de sharpness é acum. Segundo Fastl e Zwicker (2007, p. 242), 1 acum representa um som de referência, que é um ruído de banda estreita do tamanho de uma banda crítica $(B=8.5)$, com frequência central em $1 \mathrm{kHz}$ e intensidade de $60 \mathrm{~dB}$. A dependência de sharpness do modelo de bandas críticas é dada pelo fator $\mathrm{g}(B)$ e pode ser calculado de acordo com a Equação 4. Podemos notar que nela estão contidos o cálculo de loudness por bark $N^{\prime}(B)$ (Eq. 5) e o loudness total $N$, que é uma somatória do loudness de todas as bandas críticas. A equação é multiplicada por uma constante 0.11 para manter a normalização de 1 acum para o já citado som de referência.

$$
\begin{gathered}
S=0.11 \frac{\sum_{Z=1}^{n b \text { and }} B \cdot g(B) \cdot N \prime(B)}{N}(3) \\
\text { onde } g(B) \text { é dado por: } \\
\text { se } B<15, g(B)=1 \\
\text { se } B>=15, g(B)=0.066 * \exp (0.171 B)
\end{gathered}
$$




$$
\begin{aligned}
& \text { e } N^{\prime}(B) \text { é dado por: } \\
& N^{\prime}(B)=E(B)^{0.23}
\end{aligned}
$$

onde $E$ representa a somatória das magnitudes de todos os bins de uma determinada banda $B$.

Na nossa análise, o sharpness é utilizado para descrever a densidade textural das obras analisadas. Sintetizamos no Quadro 20 uso dos descritores de áudio discutidos nesta sessão.

Quadro 2 - Descritores de áudio, suas medidas e funções analíticas.

\begin{tabular}{|l|l|l|}
\hline Descritor & O que o modelo representa? & Qual a sua função na análise? \\
\hline Fluxo Espectral & $\begin{array}{l}\text { Variação da magnitude das } \\
\text { componentes espectrais entre } \\
\text { duas janelas de análise }\end{array}$ & $\begin{array}{l}\text { Descrever } \\
\text { microtemporais }\end{array}$ \\
\hline Coeficientes Bark & $\begin{array}{l}\text { Curva Espectral utilizando } \\
\text { a escala bark que modela o } \\
\text { comportamento da membrana } \\
\text { basilar }\end{array}$ & $\begin{array}{l}\text { Estimar o comportamento textu- } \\
\text { ral no plano frequêncial }\end{array}$ \\
\hline Sharpness & $\begin{array}{l}\text { Medida da percepção da densi- } \\
\text { dade sonora }\end{array}$ & $\begin{array}{l}\text { Descrever a densidade textural } \\
\text { da peça }\end{array}$ \\
\hline
\end{tabular}

Fonte: Elaborado pelos autores.

Descrição de imagem: O quadro oferece um resumo dos descritores utilizados em nossa metodologia analítica. Na coluna 1, exibimos o nome do descritor; na coluna 2, a sua medida; e na coluna 3, sua função em nossa análise.

\section{Resultados das análises}

Nesta seção apresentamos os resultados de nossas análises, os quais são baseados nos dados extraídos com os três descritores de áudio mencionados anteriormente. Os dados foram colhidos utilizando os descritores de áudio do Sonic Visualiser e, posteriormente, foram plotados utilizando a biblioteca Matplotlib (HUNTER et al., 2020) do Python. Segue a segmentação da obra utilizando o 
Análise musical de peças acusmáticas com suporte de descritores psicoacústicos Micael Antunes · Tales Botechia • Danilo Rossetti •Jônatas Manzolli

comportamento das curvas dos descritores como meio de criar seções a partir da distinção do comportamento espectral nas duas obras. Finalmente, fazemos as análises comparativas tomando por base os gráficos com os dados dos descritores.

\section{Extração de características}

A Figura 4 apresenta o descritor coeficientes barks e a Figura 5 os descritores de fluxo espectral e sharpness de Asperezas, ambas acompanhadas da segmentação (linhas pontilhadas).

Figura 4 - Descritor de coeficientes bark da peça Asperezas.

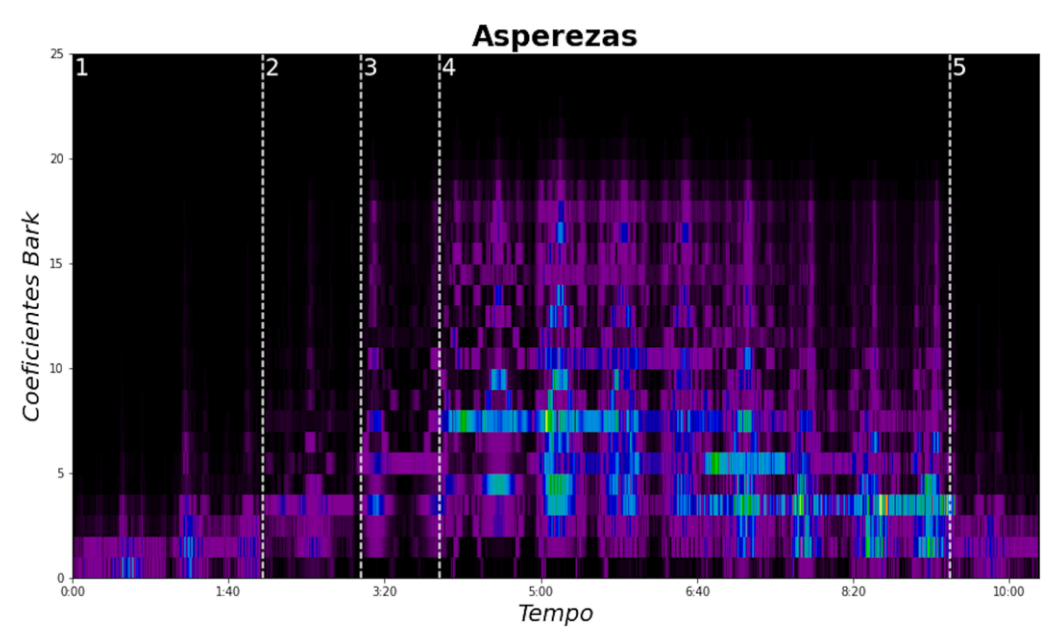

Fonte: Elaborada pelos autores.

Descrição da imagem: No eixo vertical os 26 barks e no eixo horizontal o tempo da composição. As linhas tracejadas verticais representam a segmentação. A temperatura da cor representa a intensidade do som. 
Análise musical de peças acusmáticas com suporte de descritores psicoacústicos Micael Antunes · Tales Botechia • Danilo Rossetti •Jônatas Manzolli

Figura 5 - Descritores da peça Asperezas.

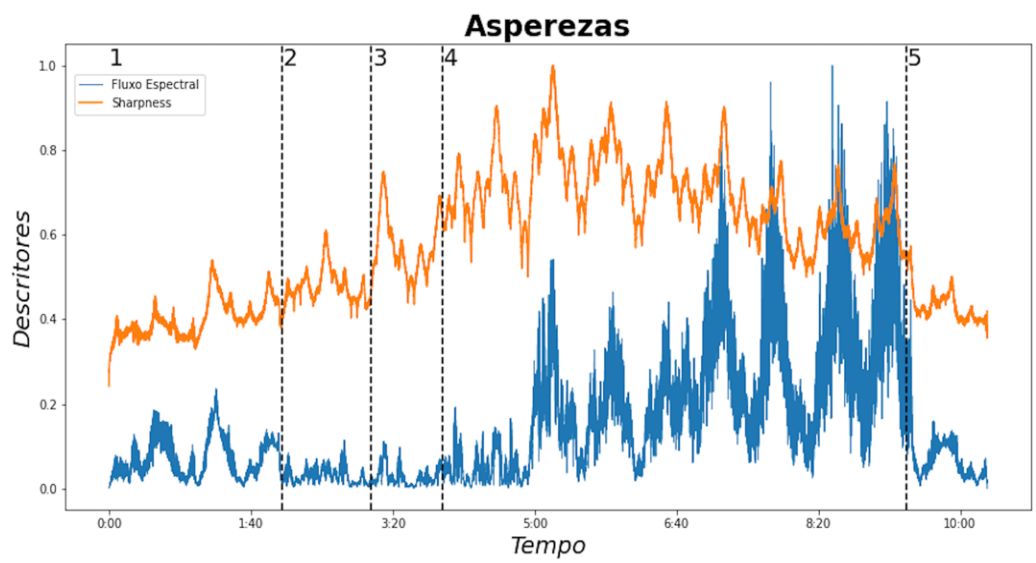

Fonte: Elaborada pelos autores.

Descrição da imagem: Em azul, o fluxo espectral e em laranja o sharpness, ambos normalizados em 1, em função do tempo da composição. As linhas tracejadas verticais representam a segmentação.

A Figura 6 apresenta o descritor coeficientes barks e a Figura 7 os descritores de fluxo espectral e sharpness de Utopia, ambas acompanhadas da segmentação com as linhas pontilhadas.

Figura 6 - Descritor de coeficientes bark da peça Utopia.

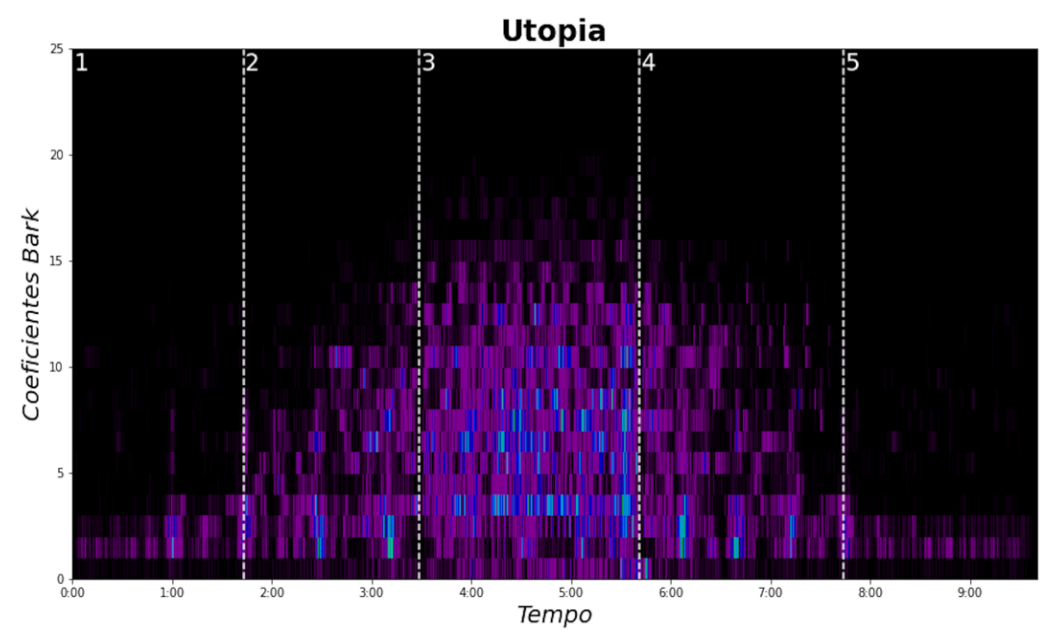

Fonte: Elaborada pelos autores. 
Análise musical de peças acusmáticas com suporte de descritores psicoacústicos Micael Antunes · Tales Botechia • Danilo Rossetti •Jônatas Manzolli

Descrição da imagem: No eixo vertical os 26 barks e no eixo horizontal o tempo da composição. As linhas tracejadas verticais representam a segmentação. A temperatura da cor representa a intensidade do som.

Figura 7 - Descritores da peça Asperezas.

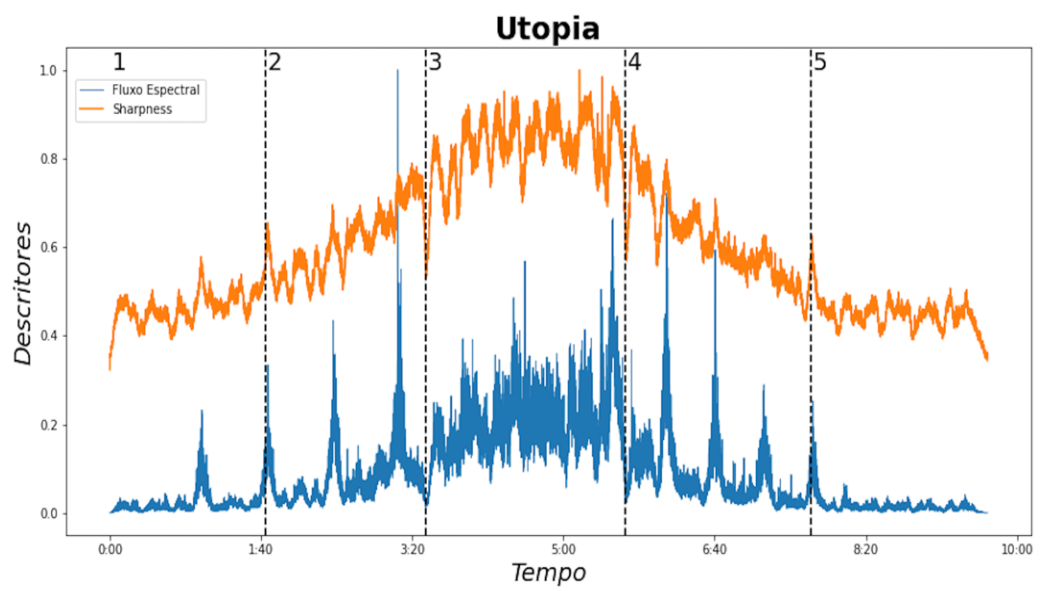

Fonte: Elaborada pelos autores.

Descrição da imagem: Em azul, o fluxo espectral e em laranja o sharpness, ambos normalizados em 1, em função do tempo da composição. As linhas tracejadas verticais representam a segmentação.

Com o objetivo de realizar uma análise detalhada das duas peças, apresentaremos nosso estudo por tópicos, sendo eles: a) segmentação das peças, b) análise do fluxo espectral, c) análise dos coeficientes bark, d) análise do sharpness.

\section{Segmentação}

Para realizar uma segmentação da peça Asperezas, observamos a variação temporal dos coeficientes bark no tempo. Na primeira seção, que ocorre de 0'a 2'22", observamos uma superconcentração de energia no grave, principalmente na região do bark 2. No segmento 2, de 2'02" a 3'05", a maior energia está no bark 4, 
e passa para o bark 6 no segmento 3, que ocorre de 3'05"a 3'55". O segmento 4, que dura de 3'55"a 9'22", revela a maior distribuição de energia em quase todos os barks até 22. Já no segmento 5, de 9'22" a 10'19", a energia se dissipa, tendo como resultado uma retomada de um nível de energia semelhante à do segmento 1. Os tempos iniciais de cada seção são exibidos na Tabela 1.

Tabela 1 - Tempo inicial de cada segmento em Asperezas.

\begin{tabular}{c|c|c|c|c|c}
\hline Segmento & $\mathbf{1}$ & $\mathbf{2}$ & $\mathbf{3}$ & $\mathbf{4}$ & $\mathbf{5}$ \\
\hline Tempo Inicial & $0^{\prime \prime}$ & $2^{\prime} 02^{\prime \prime}$ & $3^{\prime} 05^{\prime \prime}$ & $3^{\prime} 55^{\prime \prime}$ & $9^{\prime} 22^{\prime \prime}$ \\
\hline
\end{tabular}

Descrição de imagem: A Tabela 1 indica o tempo inicial de cada segmento em Asperezas, onde a primeira linha representa o segmento e a segunda linha o respectivo tempo inicial.

A segmentação de Utopia também teve como referência a distribuição de energia nos coeficientes bark e resultou em 5 seções, vide Tabela 2. O primeiro segmento, que ocorre de 0' a 1'43", mantém-se mais estável nos barks de 1 a 4 e com pouca energia. No segmento seguinte, de 1'43" a 3'29", podemos notar uma distribuição crescente e com maior concentração de energia dos barks. A princípio, esse segmento tem uma distribuição entre os barks 1 a 5, alcançando ao final uma distribuição até o bark 16. Entre 3'29" e 5'41", a distribuição de barks permanece relativamente constante, com sua energia ainda mais intensa nos barks de 1 a 16. Já no quarto segmento, o comportamento decrescente da energia nos barks acontece de 5'41" a 7'44". Começando com a distribuição entre os barks de 1 a 16, esse segmento tem uma perda de energia e reduz sua distribuição aos barks de 1 a 4 . O quinto e último segmento, de 7'44" a 9'40", tem um comportamento similar ao primeiro segmento, mantendo uma distribuição entre os barks de 1 a 4 e com energia de baixa intensidade. 
Tabela 2 - Tempo inicial de cada segmento em Utopia.

\begin{tabular}{c|c|c|c|c|c}
\hline Segmento & $\mathbf{1}$ & $\mathbf{2}$ & $\mathbf{3}$ & $\mathbf{4}$ & $\mathbf{5}$ \\
\hline Tempo Inicial & $0^{\prime \prime}$ & $1^{\prime} 43^{\prime \prime}$ & $3^{\prime} 29^{\prime \prime}$ & $5^{\prime} 41^{\prime \prime}$ & $7^{\prime} 44^{\prime \prime}$ \\
\hline \multicolumn{6}{c}{ Fonte: Elaborada pelos autores. }
\end{tabular}

Descrição de imagem: a tabela 2 indica o tempo inicial de cada segmento em Utopia, onde a primeira linha representa o segmento e a segunda linha o respectivo tempo inicial.

\section{Análise do Fluxo espectral}

A observação do descritor de fluxo espectral é reveladora da percepção da forma da peça Asperezas, dado que a obra é estruturada em variações do nível de rugosidade, por meio da manipulação da síntese FM, como descrito anteriormente. Ao observar a grande quantidade de picos e vales do gráfico do fluxo espectral, percebemos sua constante movimentação durante a peça. Ou seja, a microestrutura da peça é formada por oscilações constantes do fluxo espectral. Damos destaque ao segmento 4, pois nessa seção há o maior pico de fluxo espectral, assim como a maior oscilação desses níveis. Entendemos, a partir desses pontos, que a rugosidade ganha intensidade e protagonismo no decorrer da peça, gerando o que pode ser entendido como clímax da obra. Também é interessante notar que o uso de um grande nível de energia em barks graves nos segmentos 1 e 5 geram níveis maiores do fluxo espectral que nos segmentos 2 e 3.

Em Utopia, o gráfico do descritor de fluxo espectral coincide com a forma em arco da peça. Ele revela picos de fluxo espectral que são propostos pelo compositor como pontos de transição nos diversos materiais da peça, como descrito anteriormente. Esses picos acontecem devido à qualidade timbrística do sintetizador que, nesses momentos, utiliza um efeito de chorus que causa uma modulação nas parciais do espectro e amplia proporcionalmente a quantidade de rugosidade em relação à variação de intensidade do sinal. Vale ressaltar também que esses picos passam a descrever 
Análise musical de peças acusmáticas com suporte de descritores psicoacústicos

Micael Antunes · Tales Botechia • Danilo Rossetti •Jônatas Manzolli

curvas mais pontiagudas à medida em que a intensidade aumenta, como vemos no final do segmento 2 . Além disso, as pequenas oscilações de curvas menos acentuadas em outros momentos se relacionam às variações da densidade da textura durante a peça.

\section{Análise dos Coeficientes Bark}

Observando os coeficientes bark da peça Asperezas, percebemos que há uma grande quantidade de energia nas 5 primeiras bandas no início e no final da peça. É possível notar que há um trânsito contínuo de energia entre barks, que se deve às mudanças espectrais e de altura consequentes da síntese FM. Assim, o descritor ressalta que o desenvolvimento espectral ocorre sem rupturas ou quebras abruptas. No centro há uma maior concentração de energia em regiões específicas, com maior energia em pontos entre 2 e 22 barks. Destacamos que os segmentos de 2 a 4 reservam uma particularidade: é possível observar que a energia em alguns barks é quase constante, enquanto uma massa de frequências se movimenta em um segundo plano. Relacionando este gráfico com a escuta da peça, observamos que neste trecho ocorre uma sobreposição de duas texturas: em primeiro plano, alturas definidas; e em segundo plano, uma massa sonora com altos níveis de fusão.

Na peça Utopia há uma relação clara entre a distribuição de oitavas criada pela textura e os coeficientes bark. Nos momentos de menor distribuição de oitavas, nos segmentos 1 e 5, os barks 2 e 3 são os que contêm mais energia; já no segmento 3, o momento com maior expansão da textura, há um grande acúmulo de energia nos barks de 1 a 16, refletindo a expansão do campo textural e também um aumento de intensidade da energia espectral. 


\section{Análise do Sharpness}

Asperezas exibe os valores de sharpness em um perfil em arco, com maior energia no segmento 4. A ideia de arco é reforçada pelos níveis semelhantes de sharpness nos segmentos 1 e 5 . A peça exibe padrões simétricos na microforma, observados a partir dos perfis locais de sharpness em pequenos espaços de tempo. Esses padrões também exibem uma variação relativamente grande em seus valores. Além disso, quanto maior o nível de sharpness na peça, maior a extensão da variação.

Utopia também exibe um perfil em arco, mas com o eixo de simetria mais próximo ao centro da peça, no segmento 3. Há um perfil complexo do sharpness no tempo, mas que não demonstra grandes variações de nível em um curto espaço de tempo. Picos de sharpness ocorrem em momentos estruturais da peça, coincidindo com picos de fluxo espectral. Do mesmo modo, vales de sharpness antecipam a passagem entre segmentos, como observamos antes dos segmentos 3 e 4.

\section{Discussão: análise comparativa}

Com o objetivo de realizar uma análise comparativa entre as duas peças, nós integramos os dados do descritor coeficientes bark separando em 3 bandas, sendo elas: grave (barks de 0 a 8); médio (barks de 9 a 18); e agudo (barks de 19 a 25). A integração foi feita tendo como referência a segmentação da peça, já descrita anteriormente. 
Análise musical de peças acusmáticas com suporte de descritores psicoacústicos Micael Antunes • Tales Botechia • Danilo Rossetti •Jônatas Manzolli

Figura 8 - Descritor de bandas bark de Asperezas.

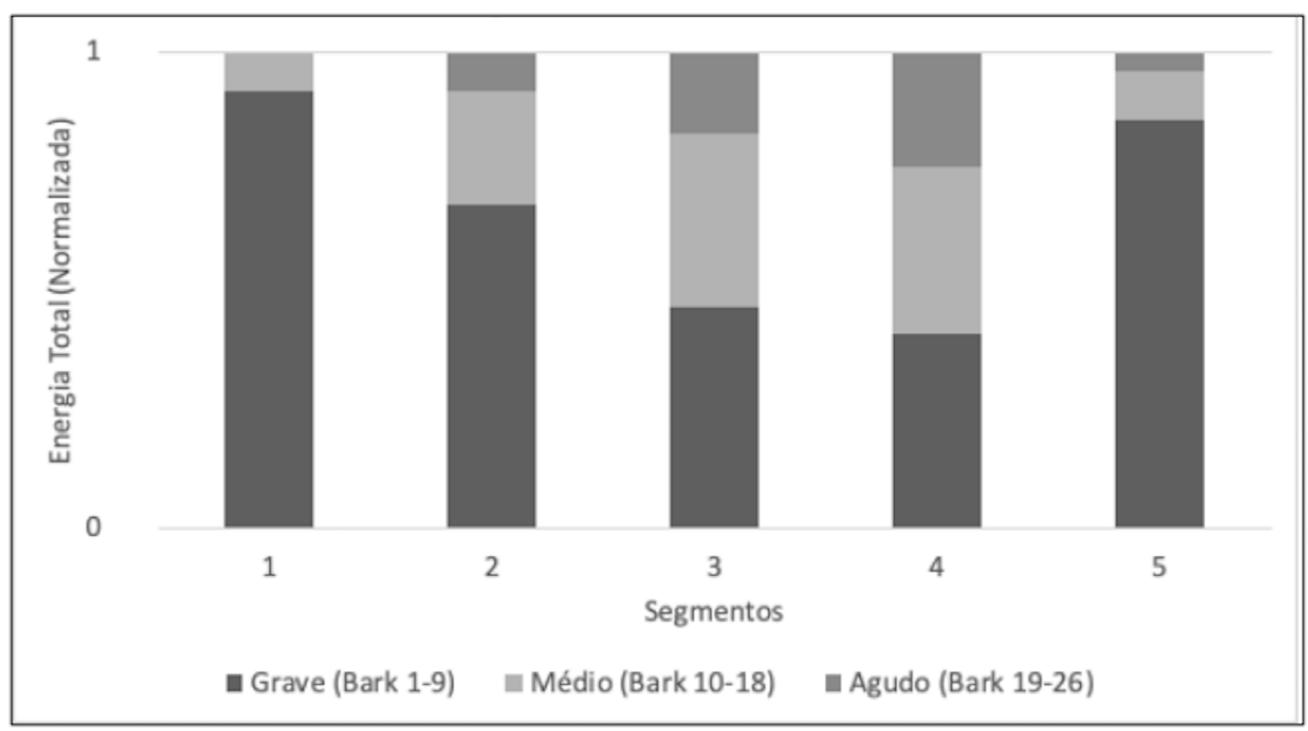

Fonte: Elaborada pelos autores.

Descrição da imagem: O eixo horizontal representa os segmentos da peça e o eixo vertical a energia normalizada das bandas.

Ao observarmos a Figura 8, notamos que a peça Asperezas tem uma grande quantidade de energia na banda grave, com pico nos segmentos 1 e 5. No quarto segmento, notamos um maior equilíbrio entre as bandas, que é construído progressivamente a partir dos segmentos 2 e 3.

Figura 9 - Descritor de bandas bark de Utopia.

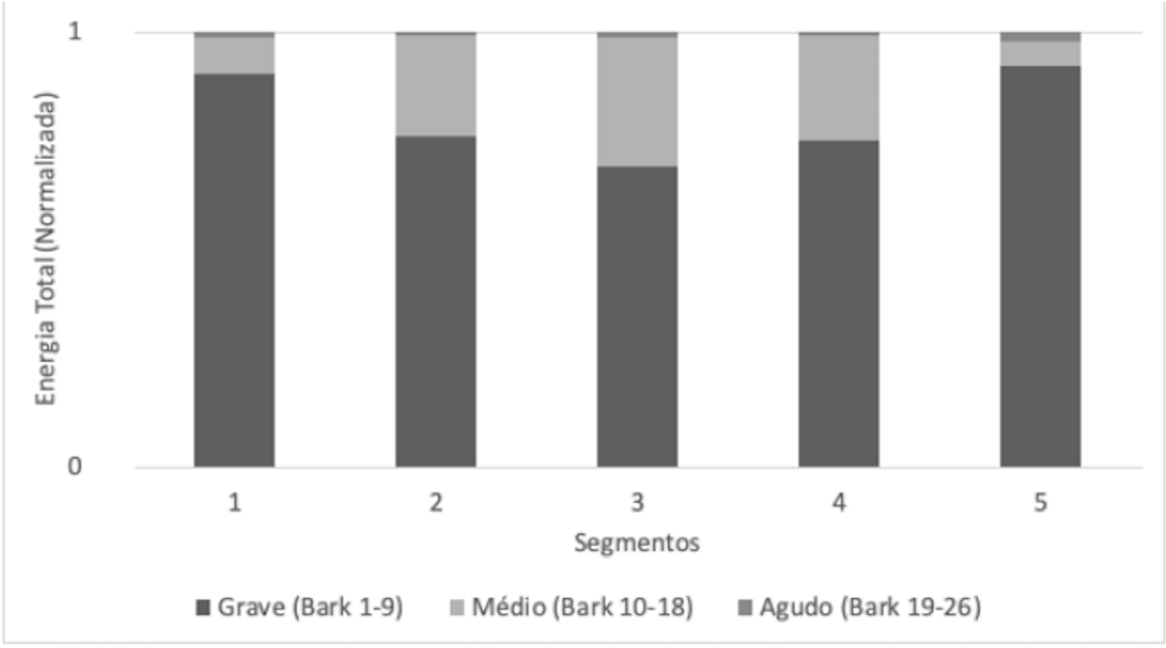

Fonte: Elaborada pelos autores. 
Análise musical de peças acusmáticas com suporte de descritores psicoacústicos

Micael Antunes · Tales Botechia • Danilo Rossetti •Jônatas Manzolli

Descrição da imagem: O eixo horizontal representa os segmentos da peça e o eixo vertical a energia normalizada das bandas.

Observando a Figura 9, notamos proporcionalmente uma ampla presença da banda grave na peça Utopia, com níveis mais altos nos segmentos 1 e 5, e menor nível no segmento 3. A banda média apresenta uma expansão de 1 a 3, com retração nas bandas 4 e 5 . Quase não há energia nas bandas agudas.

Ambas as peças demonstram, portanto, uma larga exploração das regiões grave e média em suas texturas. No entanto, Asperezas apresenta uma crescente exploração dos barks agudos, com pico no segmento 4, enquanto Utopia quase não explora a região aguda em sua textura.

Todos os gráficos apontam para uma forma em arco das peças, tendo Utopia uma simetria que tende ao centro da peça (segmento 3), enquanto Asperezas reserva sua maior energia do meio para frente, no segmento 4 . Os valores de sharpness e fluxo espectral de Utopia ocupam uma extensão menor de níveis em relação a Asperezas. Em Utopia, as mudanças de sharpness na microforma não apresentam padrões em seu comportamento, ao contrário de Asperezas.

Enquanto os níveis de fluxo espectral de Asperezas demonstram uma variação grande entre picos e vales reiterados durante toda a peça, Utopia realiza um uso mais pontual de grandes níveis de fluxo espectral, criando saliências em alguns momentos da obra. Entendemos assim que o fluxo espectral desenvolve um papel mais constante durante o desenvolvimento de Asperezas, enquanto em Utopia atua de maneira mais pontual, como articuladora da forma musical.

\section{Conclusão}

Podemos notar em ambas as peças que, apesar das diferenças de estruturação dos materiais sonoros, seus desenvolvimentos 
ocorrem através de evoluções timbrísticas, tendo como consequência a percepção de adensamento e rarefação textural, reveladas pelo descritor coeficientes bark. Além disso, é possível perceber que a estruturação no nível microtemporal de seus sons reflete a macroforma das peças. Em Asperezas, a percepção de rugosidade e intensidade planejadas a partir da síntese FM podem ser vistas também na forma da peça. Da mesma maneira, as evoluções de fade in/ fade out presentes na textura base de Utopia e a sua distribuição de oitavas se relacionam com a forma em arco da peça, além da aparição de outros sons mais pontuais próximos do segmento 3.

Destacamos que, embora presente em ambas as peças, os fenômenos de flutuação de amplitude aferidos pelo fluxo espectral são utilizados de maneiras distintas. Em Asperezas, a textura de toda a peça é constituída e permeada por fenômenos de flutuação. De outra maneira, Utopia exibe um uso pontual desse recurso, como um demarcador de fronteiras entre segmentos da peça.

Pontuamos também que a noção de emergência é pertinente na observação das peças aqui estudadas, pois a ênfase em fenômenos de flutuação de amplitude pode ser associada à ideia de emergência sonológica apresentada em entrevista por Di Scipio (ANDERSON, 2005), dado que esses fenômenos podem se manifestar de maneiras distintas a cada execução da obra. Ressaltamos isso porque fenômenos de flutuação de amplitude se comportam de maneira diferente a partir das condições de execução da peça (sala, sistema de difusão, posição do ouvinte etc.), não cabendo à análise musical definir como isso será recebido pelo ouvinte.

Notamos ainda que a noção de textura percebida nas peças está associada à de permeabilidade, mencionada por Ligeti (LIGETI, 2010), ou seja: de um som cujo timbre emerge das relações de fusão de diferentes timbres concomitantes, estimulados neste contexto pelos agregados sonoros das escalas do temperamento por igual e com o objetivo de mascarar a percepção de altura. Os descritores auxiliam assim na representação gráfica dos momentos das peças em que a fusão desses timbres é percebida. 
Análise musical de peças acusmáticas com suporte de descritores psicoacústicos Micael Antunes · Tales Botechia • Danilo Rossetti •Jônatas Manzolli

É importante ressaltar, portanto, o papel que os descritores de áudio podem desempenhar na segmentação de obras que atuam dentro do contexto da música de massas sonoras e que se apoiam nas possibilidades de fusão, segregação e transformação do timbre no seu discurso musical. Como vimos nas análises, os descritores fornecem informação visual que permite observar de maneira mais minuciosa tais transformações. Assim, conseguimos proceder à segmentação das obras aqui estudadas, abrindo caminho para a apreensão da forma musical.

Notamos a partir da simetria da curva de sharpness um potencial para detecção de padrões no contexto da música textural. Desse modo, estudos futuros podem realizar testes para verificar a pertinência do uso deste descritor para a análise de padrões emergentes da textura musical.

Trabalhos futuros poderão buscar compreender como essa abordagem analítica fomenta novos processos composicionais. Assim, podemos concluir que os métodos de síntese e geração de material sonoro ou mesmo o planejamento da forma de uma composição podem partir da exploração de parâmetros psicoacúticos, como aqui apresentado. Ou seja, os fenômenos psicoacústicos associados ao modelo de bandas críticas têm a capacidade de contribuir com o campo da composição, baseada na interação do som e suas consequências no seu discurso musical com um viés perceptivo. Por fim, entendemos que procedimentos de análise similares aos aqui apresentados também podem ser usados como ponto de partida em trabalhos experimentais na área das ciências cognitivas.

\title{
Referências
}

\begin{abstract}
ANDERSON, C. Dynamic networks of sonic interactions: An interview with Agostino Di Scipio. Computer Music Journal, Cambridge, v. 29, n. 3, p. 11-28, 2005.
\end{abstract}


Análise musical de peças acusmáticas com suporte de descritores psicoacústicos Micael Antunes · Tales Botechia • Danilo Rossetti •Jônatas Manzolli

ANTUNES, M. Redução da dissonância sensorial em uma escala temperada utilizando timbres inarmônicos: uma abordagem experimental e aplicações artísticas. 2018. 97 f. Dissertação (Mestrado em Música) - Escola de Comunicação e Artes, Universidade de São Paulo, São Paulo, 2018.

ANTUNES, M.; FARIA, R. R. A. Duas propostas de adaptação de escalas do temperamento por igual utilizando o teclado de um controlador MIDI. In: ENCONTRO INTERNACIONAL DE TEORIA E ANÁLISE MUSICAL, 4., 2017, São Paulo. Anais [...], São Paulo: USP [s.n.], 2017. p. 397-406.

ANTUNES, Micael. Asperezas. Peça Acusmática. São Paulo: 2018. Disponível em: https://soundcloud.com/micaelantunes/asperezasbinaural. Acesso em: 15 de mar. 2021.

BARBOUR, J. M. Tuning and temperament: A historical survey. New York, N.Y.: W. W. Norton \& Company, 2004.

BERRY, W. Structural functions in music. New York, N.Y.: Dover Publications Inc., 1987.

BOTECHIA, Tales. Utopia. Peça Acusmática. Campinas: 2018. Disponível em: https://soundcloud.com/tales-botechia/utopia-revisada-2018. Acesso em: 15 de mar. 2021.

BULLOCK, J. Implementing audio feature extraction in live electronic music. 2008. 244 f. Tese (Doutorado em Música) Birmingham Conservatoire, Birmingham City University, Birmingham, 2008.

BULLOCK, J. jamiebullock/LibXtract. [S.I: s.n.], 2020. Disponível em: https://github.com/jamiebullock/LibXtract. Acesso em: 9 dez. 2020.

BULLOCK, J. Libxtract: A lightweight library for audio feature extraction. In: INTERNATIONAL COMPUTER MUSIC CONFERENCE 2007, 2007, København. Proceedings of the International Computer Music Conference 2007, København: Digital Arts Forum, 2007. p. 4. CHARM. Manpage for SV Mazurka Plugin: MzSpectralFlux. Disponível em: http://www.mazurka.org.uk/software/sv/plugin/MzSpectralFlux/. Acesso em: 9 dez. 2020. 
CHOWNING, J. M. The synthesis of complex audio spectra by means of frequency modulation. Journal of the audio engineering society, Nova York, v. 21, n. 7, p. 526-534, 1973.

FASTL, H.; ZWICKER, E. Psychoacoustics: facts and models. 3. ed. Berlin ; New York: Springer, 2007.

FERRAZ, S. Análise e Percepção Textural: Peça VII, de 10 peças para Gyorgy Ligeti. Cadernos de Estudos, São Paulo: Através, p. 68-79, 1990. HUNTER, J. et al. Matplotlib: Python plotting - Matplotlib 3.3.3 documentation. Disponível em: https://matplotlib.org/. Acesso em: 14 dez. 2020.

LIGETI, G. Neuf essais sur la musique. Genève - Suisse: Éditions Contrechamps, 2010.

MACKAY, J. On the perception of density and stratification in granular sonic textures: An exploratory study. Journal of New Music Research, Londres, v. 13, n. 4, p. 171-186, 1984.

MATHEWS, M. V. et al. Theoretical and experimental explorations of the Bohlen-Pierce scale. The journal of the Acoustical Society of America, Melville, v. 84, n. 4, p. 1214-1222, 1988.

MERIC, R.; SOLOMOS, M. Audible Ecosystems and emergent sound structures in Di Scipio's music. Music philosophy helps musical analysis. Journal of interdisciplinary music studies, Graz, v. 3, n. 1-2, p. 57-76, 2008.

PARNCUTT, R. Systematic musicology and the history and future of western musical scholarship. Journal of interdisciplinary music studies, Graz, v. 1, n. 1, p. 1-32, 2007.

PEETERS, G. A large set of audio features for sound description (similarity and classification) in the CUIDADO project. CUIDADO IST Project Report, Paris, v. 54, n. 0, p. 1-25, 2004.

PIERCE, J. R. Attaining consonance in arbitrary scales. The Journal of the Acoustical Society of America, Melville, v. 40, n. 1, p. 249-249, 1966. 
PLOMP, R.; LEVELT, W. J. M. Tonal consonance and critical bandwidth. The journal of the Acoustical Society of America, Melville, v. 38, n. 4, p. 548-560, 1965.

PORRES, A. T. Modelos psicoacústicos de dissonância para eletrônica ao vivo. 2012. 224 f. Tese (Doutorado em Artes) - Escola de Comunicações e Artes, Universidade de São Paulo, São Paulo, 2012. PORRES, A. T. Processos de composição microtonal por meio do modelo de dissonância sensorial. 2007. 207 f. Dissertação (Mestrado em Música) - Instituto de Artes, Universidade Estadual de Campinas, Campinas, 2007.

PORRES, A. T.; MANZOLLI, J. Sistemas de afinação: um apanhado histórico. In: SEMINÁRIO DE MÚSICA, CIÊNCIA E TECNOLOGIA, 1., 2005, São Paulo. Procedings online. São Paulo: SciELO Brasil, 2005. p. 1-5. Disponível em: http://www.proceedings.scielo.br/pdf/smct/n1/n1a15. pdf. Acesso em: 16 Mar. 2021.

PUCKETTE, M. The Theory and Techniques of Electronic Music. Singapura: World Scientific Publishing Company, 2007.

RAY, S. Colaborações compositor-performer no Século XXI: uma idéia de trajetória e algumas perspectivas. In: XX Congresso Da Associação Nacional De Pesquisa E Pós-Graduação Em Música, 20., 2010, Florianópolis. Anais [...] Florianópolis: Udesc, 2010. p. 1310-1314. ROADS, C. Microsound. Cambridge, Mass: MIT Press, 2001. ROSSETTI, D.; MANZOLLI, J. Analysis of Granular Acousmatic Music: Representation of sound flux and emergence. Organised Sound, Cambridge, v. 24, n. 2, p. 205-216, 2019.

SCHRÖDER, J. H. Emergence and Emergency: Theoretical and Practical Considerations in Agostino Di Scipio's Works. Contemporary Music Review, Londres, v. 33, n. 1, p. 31-45, 2014.

SETHARES, W. A. Tuning, timbre, spectrum, scale. Berlin: Springer Science \& Business Media, 1998.

SMITH, J. O.; ABEL, J. S. Bark and ERB bilinear transforms. IEEE Transactions on Speech and Audio Processing, Nova York, v. 7, n. 6, p. 697-708, 1999. 
Análise musical de peças acusmáticas com suporte de descritores psicoacústicos Micael Antunes · Tales Botechia • Danilo Rossetti •Jônatas Manzolli

TENNEY, J. A history of 'consonance' and 'dissonance'. Nova York: Excelsior Music Publishing Company, 1988.

VASSILAKIS, P. N. Perceptual and physical properties of amplitude fluctuation and their musical significance. 2001. 329 f. PhD Thesis (Doutorado em Etnomusicologia) - (Faculdade/Instituto/Departamento ??), University of California, Los Angeles, Califórnia, 2001.

VIEIRA, W. Composição textural assistida por computador. 2016. 276 f. Tese (Doutorado em Música) - Herb Alpert School of Music, Universidade Estadual de Campinas, Campinas, 2016.

VON HELMHOLTZ, H. On the Sensation of Tones. 2. ed. New York: Dover, New York, 1954.

XENAKIS, I. Formalized music: thought and mathematics in composition. Maesteg: Pendragon Press, 1992.

ZWICKER, E.; FLOTTORP, G.; STEVENS, S. S. Critical Band Width in Loudness Summation. The Journal of the Acoustical Society of America, Melville, v. 29, n. 5, p. 548-557, 1957. 